\title{
GSTP1 as a novel target in radiation induced lung injury
}

\author{
Xiao Lei ${ }^{\dagger}$, Lehui $\mathrm{Du}^{\dagger}$, Wei Yư ${ }^{\dagger}$, Yao Wang, Na Ma and Baolin Qu* (]
}

\begin{abstract}
The glutathione S-transferase P1(GSTP1) is an isoenzyme in the glutathione-S transferases (GSTs) enzyme system, which is the most abundant GSTs expressed in adult lungs. Recent research shows that GSTP1 is closely related to the regulation of cell oxidative stress, inhibition of cell apoptosis and promotion of cytotoxic metabolism. Interestingly, there is evidence that GSTP1 single nucleotide polymorphisms (SNP) 105Ile/Nal related to the risk of radiation induced lung injury (RILI) development, which strongly suggests that GSTP1 is closely associated with the occurrence and development of RILI. In this review, we discuss our understanding of the role of GSTP1 in RILI and its possible mechanism.
\end{abstract}

Keywords: Radiation induced lung injury, GSTP1, Inflammatory response, Fibrosis

\section{Background}

Radiotherapy is one of the main treatments for malignant tumors, it brings great benefits for tumor patients, which could significantly improve the quality of the life and prolong the survival [1]. However, Radiation induced lung injury (RILI) is the main dose-limiting toxicity of thoracic radiation, which seriously affects the implementation of radiotherapy plan and patients' prognosis [2,3]. Although the rapid developments of medical imaging, computer technologies and radiotherapy equipment assist in the transformation of radiotherapy from traditional radiotherapy to precision radiotherapy, RILI remains to be the most common side effect for lung cancer patients, with $5 \%-36 \%$ of patients experiencing symptomatic (grade 2-5) RILI [3-5]. On the one hand, the advanced radiotherapy technology cannot avoid the direct damage of radiation to the normal tissue around tumor completely. On the other hand, the biological off-target effect caused by radiation causes the normal tissue which is not involved in the radiation area to be also affected [6,

*Correspondence: baolinqu301@163.com

${ }^{\dagger}$ Xiao Lei, Lehui Du and Wei Yu contributed equally to this work Department of Radiation Oncology, The Fifth Medical Center

of the Chinese PLA General Hospital, Beijing, China
7]. Besides lung tissue is one of the most radiosensitive organs in human, therefore, how to reduce and prevent RILI is thus vital. At present, the main mechanism of RILI is still unclear, and there is no clinically effective drug for it. Nowadays the clinical treatment of RILI is mainly based on the use of glucocorticoids, combined with symptomatic treatment such as antibiotics, relieving cough, reducing phlegm and relieving asthma drugs, but none of them are specific treatment [8-10]. Therefore, it is urgent to explore the mechanism of RILI and find effective therapeutic strategy. Interestingly, recent research shows that GSTP1 SNP 105Ile/Val related to the risk of RILI development, which strongly suggests that GSTP1 is closely associated with the occurrence and development of RILI [11, 12]. GSTP1 SNP 105Ile/Val is a GSTP1 variant which bearing a single nucleotide polymorphism in exon 5 (Ile105Val, rs1695), its enzymatic activity is reduced by $50 \%-70 \%$ compared to the wild-type GSTP1 $[11,13]$. Combined with the multiple functions of GSTP1 [14-16], we speculate that targeting GSTP1 may be a new more effective treatment method for RILI. In this review, we discuss current research progress of the potential role of GSTP1 in RILI and its mechanism.

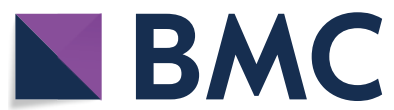

c) The Author(s) 2021. This article is licensed under a Creative Commons Attribution 4.0 International License, which permits use, sharing, adaptation, distribution and reproduction in any medium or format, as long as you give appropriate credit to the original author(s) and the source, provide a link to the Creative Commons licence, and indicate if changes were made. The images or other third party material in this article are included in the article's Creative Commons licence, unless indicated otherwise in a credit line to the material. If material is not included in the article's Creative Commons licence and your intended use is not permitted by statutory regulation or exceeds the permitted use, you will need to obtain permission directly from the copyright holder. To view a copy of this licence, visit http://creativeco mmons.org/licenses/by/4.0/. The Creative Commons Public Domain Dedication waiver (http://creativecommons.org/publicdomain/ zero/1.0/) applies to the data made available in this article, unless otherwise stated in a credit line to the data. 


\section{The potential role and its mechanisms of GSTP1 in radiation induced lung injury}

GSTP1 is the most abundant protein subtype in glutathione $S$ transferase family, which mainly contains $\alpha$, $\mu, \pi, \theta$ subtypes. The GTSP 1 gene is located on chromosome 11q13, which consists of nine exons and $3.2 \mathrm{~kb}$ in length $[17,18]$. GSTP1 can catalyze the combination of glutathione (GSH) with various electrophilic and hydrophobic substances to form water-soluble compounds to be discharged from body, thereby reducing the damage of intracellular biological macromolecules $[16,19]$. It is a dimeric protein composed of two same subunits with a molecular weight of $22.5 \mathrm{kDa}$ [20]. Recent research shows that GSTP1 plays a vital role in maintaining the balance of cell oxidation and regulating cell proliferation and apoptosis [21-23]. Furthermore, clinical data finds that patients with GSTP1 SNP 105Ile/Val had significantly higher risk of radiation pneumonitis (RP) of grade $\geq 2$ $(\mathrm{P}=0.001)$, which strongly indicates that GSTP1 is closely associated with the occurrence and development of RILI [11]. Although there is no experimental study on the effect of GSTP1 on RILI, we consider that GSTP1 has the potential role to protect against RILI combining with the anti-oxidation and anti-apoptosis functions of GSTP1. The potential mechanisms of GSTP1 in RILI as follows.

\section{GSTP1 is involved in the regulation of inflammatory response}

Multiple studies have shown that GSTP1 can inhibit inflammation through multiple pathways [24-27]. The first and most important mode is via inhibiting reactive oxygen species (ROS) pathway [24, 28]. As we mentioned before, GSTP1 belongs to GST family, which can catalyze intracellular detoxification reactions so that plays role in buffering ROS [29]. Kecheng Lei shows that MNPC, a small molecule NQO1 and GSTP1 dual inhibitor, can reduce ROS reaction via inhibiting both NADPH quinone oxidoreductase 1 (NQO1) and GSTP1, leading to apoptosis and mitigated glioblastoma (GBM) cell proliferation [24]. Other studies provide evidence that GSTP1 is phase-II detoxification enzymes that reduce quinones directly to hydroquinones, eliminating the formation of ROS produced by redox cycling [30,31]. The second mode is via inhibiting LPS-stimulated MAPKs (mitogen-activated protein kinases) [32-34]. Lan Luo shows that GSTP1 can suppress lipopolysaccharides (LPS) induced excessive production of pro-inflammatory factors by inhibiting LPS-stimulated MAPKs as well as NF-kappaB activation. Besides, GSTP1 can prevent LPSinduced TNF-alpha, IL-1beta, MCP-1 and NO production. Through the above method, GSTP1 can alleviate
LPS-induced acute lung injury [33, 35]. Recent research also shows that GSTP1 can inhibit LPS-induced inflammatory response through regulating autophagy [34]. The third mode is via regulating mitochondrial energetics and cellular metabolism [36]. Marianne E Fletcher finds that inhibiting GSTP1 can aggravate pulmonary edema, inflammatory cell infiltration and other inflammatory reactions through the third mode [37]. In summary, GSTP1 could regulate inflammation response through the above three modes.

\section{GSTP1 is related to radiation induced fibrosis}

RILI includes radiation pneumonitis and radiation induced pulmonary fibrosis. It's the consequence for acute and late effects of radiation. Radiation pneumonitis occurs in 6 months after radiation while radiation induced pulmonary fibrosis occurs $>6$ months [3, 38]. Recent clinical researches show that GSTP1 is associated with radiation induced fibrosis to various tissues $[39,40]$. Hege Edvardsen followed up 92 breast cancer survivors previously treated with hypofractionated radiation therapy, did the SNPs genotype and found GSTP1 was highly associated with subcutaneous fibrosis and lung fibrosis, which might be due to participate in maintenance of the intracellular redox balance [41]. Fangming Kan utilized RNA sequencing and Gene Ontology (GO) analysis on mice liver tissue infected with Hepatitis B virus $(\mathrm{HBV})$, then he discovered GSTP1 was one of the key proteins involved in HBV-related liver fibrosis [42]. Terrazzino did the research with 257 breast cancer patients who underwent surgery plus adjuvant radiotherapy and found GSTP1 Ile105Val was significantly associated with the risk of Grade 2-3 radiation-induced fibrosis, especially in skin fibrosis [43]. Lehui Du recruited a total of 149 lung cancer patients who had received intensity modulated radiation therapy (IMRT) and did blood samples DNA extraction and genotyping, then they found an association between GSTP1 SNP 105Ile/Val and risk of RP development, which suggests the potential use of this genetic polymorphism as a predictor of RP [11]. In summary, GSTP1 involves in various tissues' radiation induced fibrosis, which indicates GSTP1 plays an important role in RILI.

\section{GSTP1 regulates radiation induced cell apoptosis}

Plenty of studies have shown that GSTP1 can regulate radiation induced apoptosis through multiple pathways [44-46]. T Wang discovered that GSTP1 Inhibited C-Jun $\mathrm{N}$-Terminal Kinase (Jnk1) signaling through interaction with the C Terminus [47], while Ruscoe JE showed that GSTP1 could inhibit radiation induced cell apoptosis via GSTP1-Jnk1 pathway [48]. GSTP1 also could inhibit the interaction between tumor necrosis factor-related 


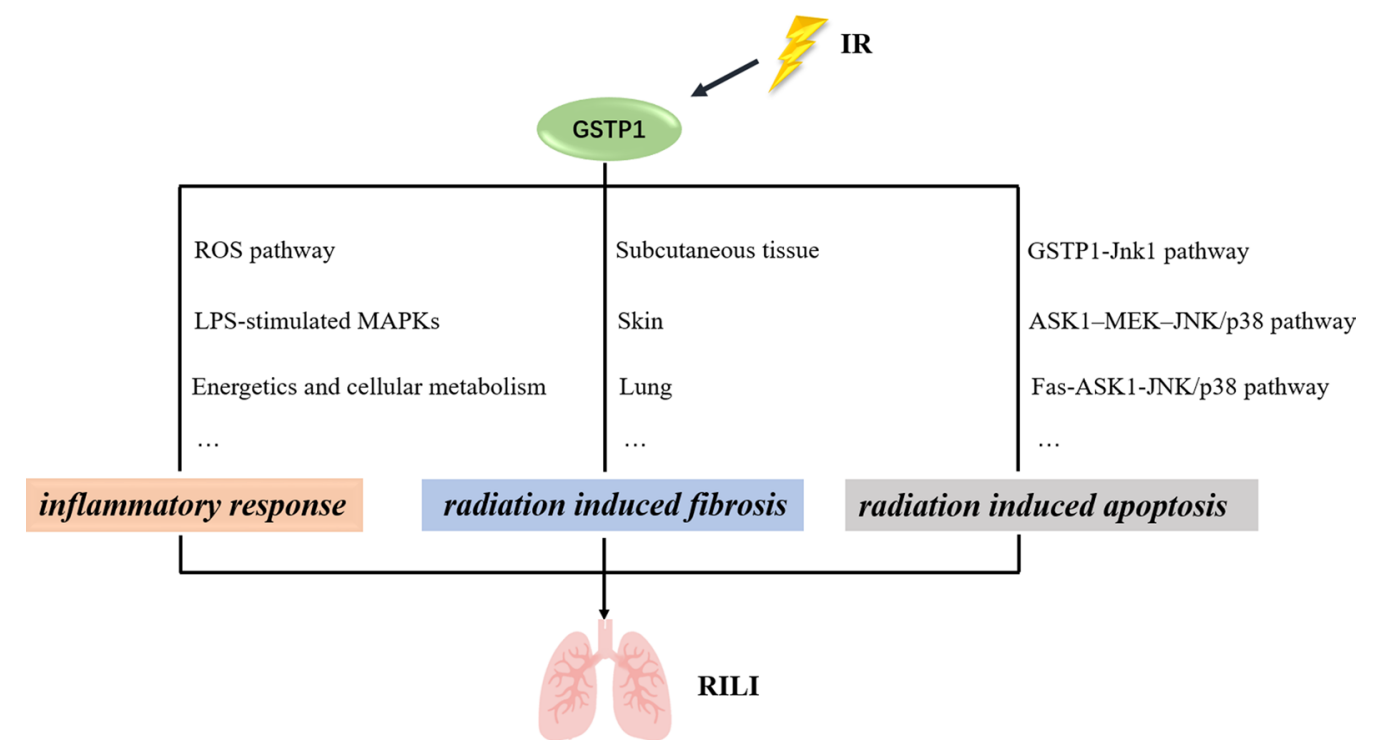

Fig. 1 Potential mechanisms of GSTP1 in RILI

receptor 2 (TRAF2) and apoptosis signal-regulating kinase 1 (ASK1) by binding to TRAF2, negatively regulated the ASK1-MEK-JNK/p38 pathway induced by tumor necrosis factor $\alpha$ (TNF $\alpha)$, which inhibited cell apoptosis [30]. However, Guyue Liu showed that GSTP1 could induce apoptosis in malignant hematologic cells via downregulation of myeloid cell leukemia-1 (Mcl-1) and cellular FLICE (FADD-like IL-1 $\beta$-converting enzyme)inhibitory protein (c-FLIP) [49]. GSTP1 also could induce apoptosis through the Fas-ASK1-JNK/p38 pathway by amplifying Fas ligand [50]. In summary, the mechanism of GSTP1 regulating cell apoptosis and proliferation is thus complicated, which need to further explore.

\section{Perspective}

Although the development of medical technology has greatly alleviated the occurrence of adverse events of radiotherapy, lung tissue, as one of the most radiosensitive organs, is impossible to avoid damage to patients with chest tumors after radiotherapy [51-54]. Therefore, RILI is still the most common complication after radiotherapy for patients with chest tumors [3]. RILI includes radiation pneumonitis and radiation induced pulmonary fibrosis, the pathogenesis of which is still not completely clear [55]. Mainstream researches show that the mechanism of RILI may be because ionizing radiation can directly cause DNA damage and a large number of free radicals in lung tissue cells, which can mediate and amplify the damage of alveolar epithelial cells and vascular endothelial cells by promoting oxidative stress, vascular damage and inflammatory response, further leading to RILI [56-58]. Nowadays there is no specific therapeutic drug for radiation-induced lung injury, only glucocorticoids are used in the treatment of RILI, but it's not specific treatment [10]. Therefore, there is an urgent need to find a strategy to prevent or treat RILI in clinic. GSTP1 is a protein subtype in glutathione $\mathrm{S}$ transferase family, which shows great role in maintaining the balance of cell oxidation and regulating cell proliferation and apoptosis $[23,59]$. Although there is no experimental research indicating GSTP1 plays crucial role in RILI, Du's research presents GSTP1 SNP 105Ile/Val is a vital predictor of RILI, which raise our interest that GSTP1 may have the potential role to protect against RILI [11]. The potential mechanisms of GSTP1 protecting against RILI have already present in this review, which means that GSTP1 may be the significant target for clinical protection of RILI (Fig. 1). However, recent research shows that GSTP1 is closely related to tumor occurrence and prognosis [6063]. GSTP1 is highly expressed in a variety of tumor tissues and can be used as a biomarker in tumors [64-66]. Therefore, research needs to further explore the role of GSTP1 in tumor tissue after radiotherapy, so that clinic can make individual treatment for patients to reduce the occurrence of RILI.

\section{Conclusion}

All in all, GSTP1 is an important predictor of RILI and may play vital role in prevention of RILI. The potential mechanisms of GSTP1 in RILI include inflammatory response, radiation induced fibrosis and cell apoptosis. However, there is still no clear experiment to show the 
role and mechanism of GSTP1 in RILI. This is a research idea we provide for everyone, which could make better individualized treatment strategies for the clinic. Furthermore, although related studies have shown that GSTP1 is closely related to the occurrence and development of tumors, there is no research showing the role of GSTP1 in tumor tissues after radiotherapy. Till now, there are several evidences showing that targeting GSTP1 can have a synergistic effect with chemotherapy drugs, but no relevant study shown between GSTP1 and chemotherapy-induced lung injury [66-68]. If the changes in the expression or activity of GSTP1 protein could be controlled to increase the destructive effect of radiotherapy on tumor tissues, while reducing radiation damage to the normal lung tissue, it will have extremely important medical significance for the treatment and prognosis of patients with thoracic tumors. This is the core purpose of this review.

\section{Acknowledgements}

Not applicable.

\section{Authors' contributions}

$\mathrm{XL}$ and LD made the manuscript. WY did the perspective part. NM and YW helped collect clinic data. BQ participated in the writing of paper and revision of manuscript. All authors read and approved the final manuscript.

\section{Funding}

This study was supported in part by the grants from National Natural Science Foundation of China (No. 82003387), Military Research Plan (No. 20BJZ40) and The Second Medical Center \& National Clinical Research Center for Geriatric Diseases, Chinese PLA General Hospital (NCRCG-PLAGH-2020003).

\section{Availability of data and materials}

The datasets are available under reasonable request.

\section{Declarations}

Ethics approval and consent to participate

Not applicable.

\section{Consent for publication}

Not applicable.

\section{Competing interests}

The authors declare that they have no competing interests.

Received: 26 April 2021 Accepted: 4 July 2021

Published online: 08 July 2021

\section{References}

1. Citrin DE. Recent developments in radiotherapy. N Engl J Med. 2017;377(11):1065-75.

2. Giuranno L, et al. Radiation-induced lung injury (RILI). Front Oncol. 2019;9:877.

3. Hanania AN, et al. Radiation-induced lung injury: assessment and management. Chest. 2019;156(1):150-62.

4. De Ruysscher D, et al. Radiotherapy toxicity. Nat Rev Dis Primers. 2019:5(1):13.

5. Xia $C$, et al. Prevention and treatment of radiation-induced lung injury. Future Med Chem. 2020;12(23):2161-73.
6. Alizadeh E, Orlando TM, Sanche L. Biomolecular damage induced by ionizing radiation: the direct and indirect effects of low-energy electrons on DNA. Annu Rev Phys Chem. 2015;66:379-98.

7. Pouget JP, Georgakilas AG, Ravanat JL. Targeted and off-target (bystander and abscopal) effects of radiation therapy: redox mechanisms and risk/ benefit analysis. Antioxid Redox Signal. 2018;29(15):1447-87.

8. Xue J, et al. Gene-modified mesenchymal stem cells protect against radiation-induced lung injury. Mol Ther. 2013;21(2):456-65.

9. Zhou J, et al. Lung tissue extracellular matrix-derived hydrogels protect against radiation-induced lung injury by suppressing epithelial-mesenchymal transition. J Cell Physiol. 2020;235(3):2377-88.

10. Jin $\mathrm{H}$, et al. Radiation-induced lung fibrosis: preclinical animal models and therapeutic strategies. Cancers (Basel). 2020;12(6):1561.

11. Du L, et al. GSTP1 Ile105Val polymorphism might be associated with the risk of radiation pneumonitis among lung cancer patients in Chinese population: a prospective study. J Cancer. 2018;9(4):726-35.

12. Du $L$, et al. Association of DNA repair gene polymorphisms with the risk of radiation pneumonitis in lung cancer patients. Oncotarget. 2018;9(1):958-68.

13. Ali-Osman F, et al. Molecular cloning, characterization, and expression in Escherichia coli of full-length cDNAs of three human glutathione S-transferase Pi gene variants. Evidence for differential catalytic activity of the encoded proteins. J Biol Chem. 1997;272(15):10004-12.

14. Nørskov MS, Dahl M, Tybjærg-Hansen A. Genetic Variation in GSTP1, lung function, risk of lung cancer, and mortality. J Thorac Oncol. 2017;12(11):1664-72.

15. Dong SC, et al. Glutathione S-transferase $\pi$ : a potential role in antitumor therapy. Drug Des Devel Ther. 2018;12:3535-47.

16. Chatterjee A, Gupta S. The multifaceted role of glutathione S-transferases in cancer. Cancer Lett. 2018;433:33-42.

17. Cui J, et al. GSTP1 and cancer: expression, methylation, polymorphisms and signaling (Review). Int J Oncol. 2020;56(4):867-78.

18. Cowell IG, et al. The structure of the human glutathione S-transferase pi gene. Biochem J. 1988;255(1):79-83.

19. Mcllwain CC, Townsend DM, Tew KD. Glutathione S-transferase polymorphisms: cancer incidence and therapy. Oncogene. 2006;25(11):1639-48.

20. FeiFei W, et al. FBX8 degrades GSTP1 through ubiquitination to suppress colorectal cancer progression. Cell Death Dis. 2019;10(5):351.

21. Mian OY, et al. GSTP1 Loss results in accumulation of oxidative DNA base damage and promotes prostate cancer cell survival following exposure to protracted oxidative stress. Prostate. 2016;76(2):199-206.

22. Qiu K, Zheng Z, Huang Y. Long intergenic noncoding RNA 00844 promotes apoptosis and represses proliferation of prostate cancer cells through upregulating GSTP1 by recruiting EBF1. J Cell Physiol. 2020;235(11):8472-85.

23. Lei $\mathrm{K}$, et al. Discovery of a dual inhibitor of NQO1 and GSTP1 for treating glioblastoma. J Hematol Oncol. 2020;13(1):141.

24. Spiteri MA, et al. Polymorphisms at the glutathione S-transferase, GSTP1 locus: a novel mechanism for susceptibility and development of atopic airway inflammation. Allergy. 2000;55(Suppl 61):15-20.

25. De Nunzio C, et al. The controversial relationship between benign prostatic hyperplasia and prostate cancer: the role of inflammation. Eur Urol. 2011;60(1):106-17.

26. Malerba G, Pignatti PF. A review of asthma genetics: gene expression studies and recent candidates. J Appl Genet. 2005;46(1):93-104.

27. Ściskalska M, Milnerowicz H. Activity of glutathione S-transferase and its $\pi$ isoenzyme in the context of single nucleotide polymorphism in the GSTP1 gene (rs1695) and tobacco smoke exposure in the patients with acute pancreatitis and healthy subjects. Biomed Pharmacother. 2021;140:111589.

28. Uys JD, Mulholland PJ, Townsend DM. Glutathione and redox signaling in substance abuse. Biomed Pharmacother. 2014;68(6):799-807.

29. Guo Z, et al. DCAF1 regulates Treg senescence via the ROS axis during immunological aging. J Clin Invest. 2020;130(11):5893-908.

30. Wu Y, et al. Human glutathione S-transferase P1-1 interacts with TRAF2 and regulates TRAF2-ASK1 signals. Oncogene. 2006;25(42):5787-800.

31. Yang Y, et al. GSTpi regulates VE-cadherin stabilization through promoting S-glutathionylation of Src. Redox Biol. 2020;30:101416.

32. Bartolini $D$, et al. Glutathione S-transferase pi expression regulates the Nrf2-dependent response to hormetic diselenides. Free Radic Biol Med. 2015:88(Pt B):466-80. 
33. Luo L, et al. Recombinant protein glutathione S-transferases P1 attenuates inflammation in mice. Mol Immunol. 2009;46(5):848-57.

34. Bi X, et al. GSTP1 inhibits LPS-induced inflammatory response through regulating autophagy in THP-1 cells. Inflammation. 2020;43(3):1157-69.

35. Jones JT, et al. Glutathione S-transferase pi modulates NF-kB activation and pro-inflammatory responses in lung epithelial cells. Redox Biol. 2016:8:375-82.

36. Rivera-Ingraham GA, et al. Salinity stress from the perspective of the energy-redox axis: lessons from a marine intertidal flatworm. Redox Biol. 2016;10:53-64.

37. Fletcher ME, et al. Influence of glutathione-S-transferase (GST) inhibition on lung epithelial cell injury: role of oxidative stress and metabolism. Am J Physiol Lung Cell Mol Physiol. 2015;308(12):L1274-85.

38. Giridhar $P$, et al. Radiation induced lung injury: prediction, assessment and management. Asian Pac J Cancer Prev. 2015;16(7):2613-7.

39. Edvardsen $\mathrm{H}$, et al. Germline glutathione S-transferase variants in breast cancer: relation to diagnosis and cutaneous long-term adverse effects after two fractionation patterns of radiotherapy. Int J Radiat Oncol Biol Phys. 2007;67(4):1163-71.

40. Terrazzino S, et al. Common variants of eNOS and XRCC1 genes may predict acute skin toxicity in breast cancer patients receiving radiotherapy after breast conserving surgery. Radiother Oncol. 2012;103(2):199-205.

41. Edvardsen $\mathrm{H}$, et al. SNP in TXNRD2 associated with radiation-induced fibrosis: a study of genetic variation in reactive oxygen species metabolism and signaling. Int J Radiat Oncol Biol Phys. 2013;86(4):791-9.

42. Kan F, et al. Proteomic and transcriptomic studies of HBV-associated liver fibrosis of an AAV-HBV-infected mouse model. BMC Genomics. 2017;18(1):641.

43. Terrazzino S, et al. Common variants of GSTP1, GSTA1, and TGF $\beta 1$ are associated with the risk of radiation-induced fibrosis in breast cancer patients. Int J Radiat Oncol Biol Phys. 2012;83(2):504-11.

44. Sau A, et al. Targeting GSTP1-1 induces JNK activation and leads to apoptosis in cisplatin-sensitive and -resistant human osteosarcoma cell lines. Mol Biosyst. 2012;8(4):994-1006.

45. Mohammad J, et al. JNK inhibition blocks piperlongumine-induced cell death and transcriptional activation of heme oxygenase-1 in pancreatic cancer cells. Apoptosis. 2019;24(9-10):730-44.

46. Yang $X$, et al. Novel oxadiazole analogues derived from ethacrynic acid: design, synthesis, and structure-activity relationships in inhibiting the activity of glutathione S-transferase P1-1 and cancer cell proliferation. J Med Chem. 2010;53(3):1015-22.

47. Wang T, et al. Glutathione S-transferase P1-1 (GSTP1-1) inhibits c-Jun $\mathrm{N}$-terminal kinase (JNK1) signaling through interaction with the $\mathrm{C}$ terminus. J Biol Chem. 2001;276(24):20999-1003.

48. Ruscoe JE, et al. Pharmacologic or genetic manipulation of glutathione S-transferase P1-1 (GSTpi) influences cell proliferation pathways. J Pharmacol Exp Ther. 2001;298(1):339-45.

49. Liu G, et al. Ethacrynic acid oxadiazole analogs induce apoptosis in malignant hematologic cells through downregulation of $\mathrm{Mcl}-1$ and c-FLIP, which was attenuated by GSTP1-1. Mol Cancer Ther. 2013;12(9):1837-47.

50. Mcmillan D, et al. Attenuation of GSTP1 decreases Fas SGlutathionylationmediated lung epithelial cell apoptosis and fibrotic remodeling. Free Radical Biol Med. 2014;76:S164.
51. Ahmad SS, et al. Advances in radiotherapy. Bmj. 2012;345:e7765.

52. Pollom EL, et al. Normal tissue constraints for abdominal and thoracic stereotactic body radiotherapy. Semin Radiat Oncol. 2017;27(3):197-208.

53. Duijm $M$, et al. Dose and volume of the irradiated main bronchi and related side effects in the treatment of central lung tumors with stereotactic radiotherapy. Semin Radiat Oncol. 2016;26(2):140-8.

54. Huang $Y$, et al. The cellular and molecular mechanism of radiationinduced lung injury. Med Sci Monit. 2017;23:3446-50.

55. Bledsoe TJ, Nath SK, Decker RH. Radiation pneumonitis. Clin Chest Med. 2017;38(2):201-8

56. Xu S, Liu C, Ji HL. Concise review: therapeutic potential of the mesenchymal stem cell derived secretome and extracellular vesicles for radiationinduced lung injury: progress and hypotheses. Stem Cells Transl Med. 2019;8(4):344-54.

57. Guan D, et al. Lung endothelial cell-targeted peptide-guided bFGF promotes the regeneration after radiation induced lung injury. Biomaterials. 2018;184:10-9.

58. Meziani $L$, et al. CSF1R inhibition prevents radiation pulmonary fibrosis by depletion of interstitial macrophages. Eur Respir J. 2018;51(3):1702120.

59. Townsend DM, Tew KD. Cancer drugs, genetic variation and the glutathione-S-transferase gene family. Am J Pharmaco Genomics. 2003;3(3):157-72

60. Gurioli G, et al. GSTP1 methylation in cancer: a liquid biopsy biomarker? Clin Chem Lab Med. 2018;56(5):702-17.

61. Okamura T, et al. Phosphorylation of glutathione S-transferase P1 (GSTP1) by epidermal growth factor receptor (EGFR) promotes formation of the GSTP1-c-Jun N-terminal kinase (JNK) complex and suppresses JNK downstream signaling and apoptosis in brain tumor cells. J Biol Chem. 2015;290(52):30866-78

62. Yang $M$, et al. CLDN6 promotes chemoresistance through GSTP1 in human breast cancer. J Exp Clin Cancer Res. 2017;36(1):157.

63. Lei $\mathrm{K}$, et al. C/EBP $\beta$ mediates NQO1 and GSTP1 anti-oxidative reductases expression in glioblastoma, promoting brain tumor proliferation. Redox Biol. 2020;34:101578.

64. Li Q, et al. Association of GSTP1 and P16 promoter methylation with the risk of HBV-related hepatocellular carcinoma: a meta-analysis. Onco Targets Ther. 2018;11:5789-96.

65. Patel PG, et al. A three-gene DNA methylation biomarker accurately classifies early stage prostate cancer. Prostate. 2019;79(14):1705-14.

66. Yang SJ, et al. Predictive role of GSTP1-containing exosomes in chemotherapy-resistant breast cancer. Gene. 2017;623:5-14.

67. Li J, et al. Transcriptional activation of Gstp1 by MEK/ERK signaling confers chemo-resistance to cisplatin in lung cancer stem cells. Front Oncol. 2019;9:476.

68. Zhang P, et al. DLJ14, a novel chemo-sensitization agent, enhances therapeutic effects of adriamycin against MCF-7/A cells both in vitro and in vivo. J Pharm Pharmacol. 2014;66(3):398-407.

\section{Publisher's Note}

Springer Nature remains neutral with regard to jurisdictional claims in published maps and institutional affiliations.

Ready to submit your research? Choose BMC and benefit from

- fast, convenient online submission

- thorough peer review by experienced researchers in your field

- rapid publication on acceptance

- support for research data, including large and complex data types

- gold Open Access which fosters wider collaboration and increased citations

- maximum visibility for your research: over 100M website views per year

At BMC, research is always in progress.

Learn more biomedcentral.com/submissions 